\title{
Interseismic Coupling-Based Earthquake and Tsunami Scenarios for the Nankai Trough
}

Hannah Baranes

University of Massachusetts Amherst

Jon D. Woodruff

University of Massachusetts Amherst

John P. Loveless

Smith College, jloveles@smith.edu

M. Hyodo

Japan Agency for Marine-Earth Science and TechnologyYokohama, Japan

Follow this and additional works at: https://scholarworks.smith.edu/geo_facpubs

Part of the Geology Commons, and the Geophysics and Seismology Commons

\section{Recommended Citation}

Baranes, Hannah; Woodruff, Jon D.; Loveless, John P.; and Hyodo, M., "Interseismic Coupling-Based Earthquake and Tsunami Scenarios for the Nankai Trough" (2018). Geosciences: Faculty Publications, Smith College, Northampton, MA.

https://scholarworks.smith.edu/geo_facpubs/26 


\section{Geophysical Research Letters}

\section{RESEARCH LETTER}

10.1002/2018GL077329

Key Points:

- Methods are demonstrated for constructing earthquake rupture scenarios based on the scaling of interseismic coupling to coseismic slip

- The resulting ground deformation and tsunami are similar to the largest known Nankai earthquake and an independent quasi-dynamic model

- Results show coupling mirrors slip for a full-margin rupture and provide evidence for a region of focused subsidence in western Shikoku

Supporting Information:

- Supporting Information S1

- Data Set S1

Correspondence to:

H. Baranes,

hbaranes@geo.umass.edu

\section{Citation:}

Baranes, H., Woodruff, J. D., Loveless, J. P., \& Hyodo, M. (2018). Interseismic coupling-based earthquake and tsunami scenarios for the Nankai Trough. Geophysical Research Letters, 45, 2986-2994. https://doi.org/10.1002/ 2018GL077329

Received 29 JAN 2018 Accepted 17 MAR 2018 Accepted article online 26 MAR 2018 Published online 6 APR 2018

\section{Interseismic Coupling-Based Earthquake and Tsunami Scenarios for the Nankai Trough}

\author{
H. Baranes ${ }^{1} \mathbb{D}$, J. D. Woodruff' ${ }^{1}$, J. P. Loveless ${ }^{2}$ iD, and M. Hyodo ${ }^{3}$ \\ ${ }^{1}$ Department of Geosciences, University of Massachusetts Amherst, Amherst, MA, USA, ${ }^{2}$ Department of Geosciences, Smith \\ College, Northampton, MA, USA, ${ }^{3}$ Research and Development Center for Earthquake and Tsunami, Japan Agency for \\ Marine-Earth Science and Technology, Yokohama, Japan
}

\begin{abstract}
Theoretical modeling and investigations of recent subduction zone earthquakes show that geodetic estimates of interseismic coupling and the spatial distribution of coseismic rupture are correlated. However, the utility of contemporary coupling in guiding construction of rupture scenarios has not been evaluated on the world's most hazardous faults. Here we demonstrate methods for scaling coupling to slip to create rupture models for southwestern Japan's Nankai Trough. Results show that coupling-based models produce distributions of ground surface deformation and tsunami inundation that are similar to historical and geologic records of the largest known Nankai earthquake in CE 1707 and to an independent, quasi-dynamic rupture model. Notably, these models and records all support focused subsidence around western Shikoku that makes the region particularly vulnerable to flooding. Results imply that contemporary coupling mirrors the slip distribution of a full-margin, 1707-type rupture, and Global Positioning System measurements of surface motion are connected with the trough's physical characteristics.
\end{abstract}

Plain Language Summary In regions that are vulnerable to earthquakes, constructing rupture scenarios based on scientific observations of faults is key to managing risk. High-precision Global Positioning System measurements that track the motion of Earth's crust can be used to estimate interseismic coupling, which is a measure of frictional locking along fault interfaces that causes stress buildup between earthquakes. Past studies have shown that the distribution of coupling preceding an earthquake is correlated with rupture during an earthquake. We demonstrate methods for constructing rupture scenarios based on estimates of coupling for southwestern Japan's Nankai Trough, where a magnitude 8-9 earthquake is likely to occur within the next few decades. Modeled ground surface deformation and tsunami inundation for these coupling-based rupture scenarios are similar to historical and geologic records of the largest known Nankai earthquake in CE 1707 and to an independent rupture model based on the trough's physical characteristics. Notably, these models and records all show that the ground surface around western Shikoku sinks during earthquake rupture and becomes particularly vulnerable to tsunami flooding. Our results imply that contemporary coupling mirrors the rupture pattern of the Nankai Trough's largest known historical event and that Global Positioning System measurements of surface motion are connected with the trough's physical characteristics.

\section{Introduction}

Subduction zone earthquakes and accompanying tsunamis have catastrophically damaged coastal communities around the world. Recent advances in space geodesy that offer unprecedented insight into the present-day kinematic behavior of faults have the potential to significantly advance earthquake hazard assessment (Feigl et al., 1993; Hager et al., 1991). High-precision measurements of crustal motion can be used to estimate spatiotemporal variation in slip deficit that accumulates where a fault interface is locked by friction between earthquakes (Loveless \& Meade, 2016; McCaffrey et al., 2000; S. Nishimura \& Hashimoto, 2006). Interseismic coupling is the ratio of this estimated slip deficit to relative plate motion. Both numerical simulations (Kaneko et al., 2010) and observations from the 2010 Maule (Moreno et al., 2010), 2011 Tōhoku (Loveless \& Meade, 2011), and 2012 Nicoya (Protti et al., 2014) megathrust earthquakes have provided evidence for correlation between the estimated spatial distributions of interseismic coupling and subsequent coseismic slip. These studies have posited that coupling may be used to anticipate the spatial extent of future rupture. Here we test this correlation on one of the world's most hazardous faults by creating rupture scenarios from coupling distributions and evaluating the scenarios by comparing simulated ground surface deformation and tsunami inundation to historical and geologic observations. 

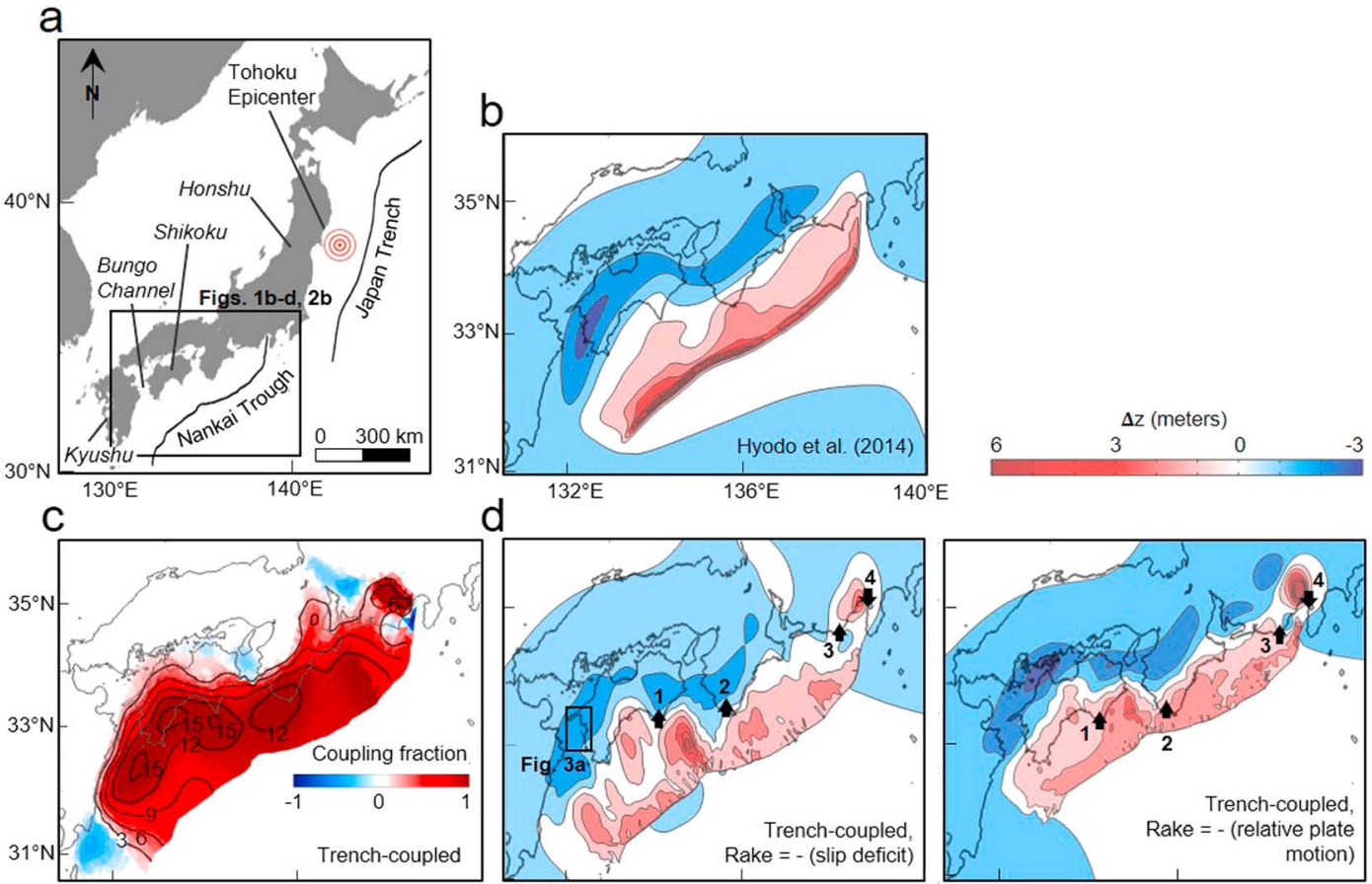

d
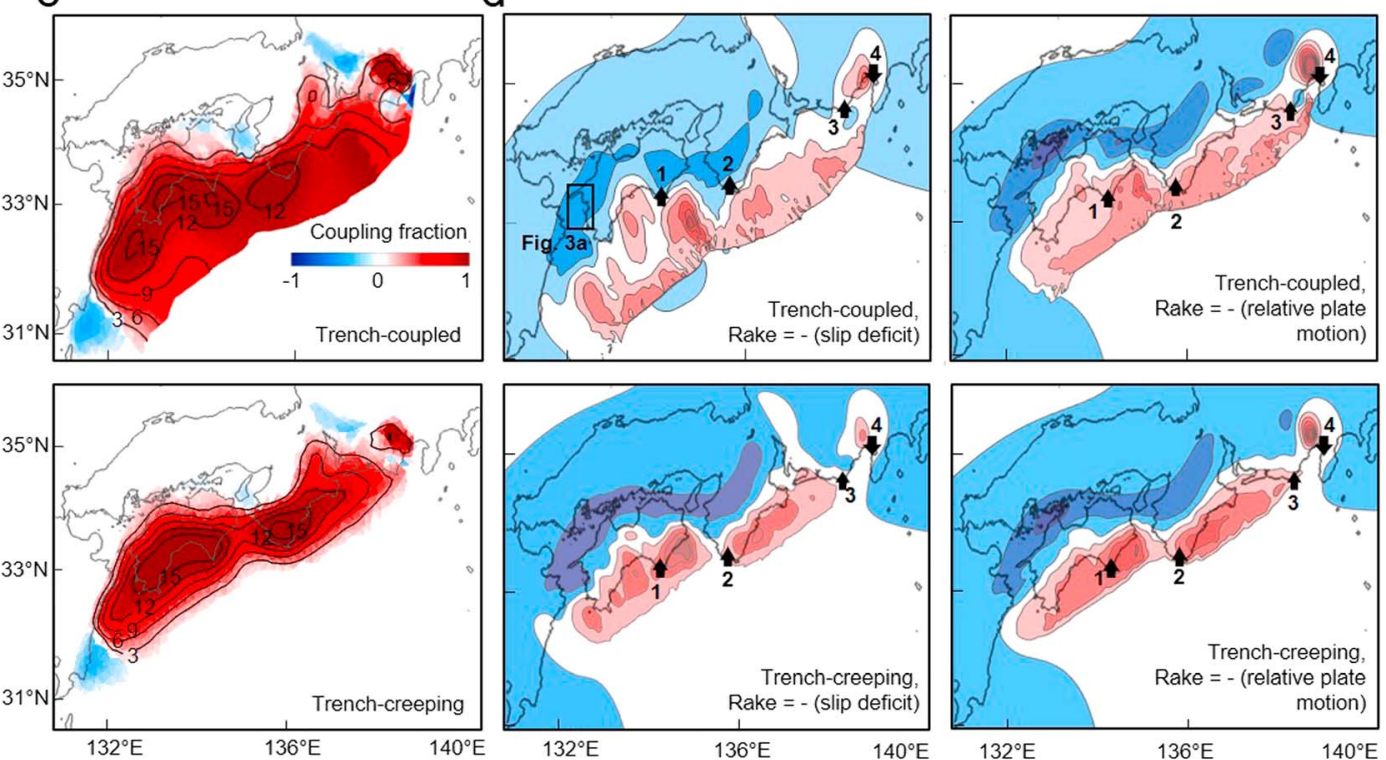

Figure 1. Nankai Trough earthquake scenarios. (a) Regional setting of the Nankai Trough. (b) Vertical surface displacement for a previously published and independent quasi-dynamic rupture model by Hyodo et al. (2014). (c) Nankai Trough coupling fraction for the "trench-coupled" and "trench-creeping" cases (Loveless \& Meade, 2016), where coupling fraction is defined as the ratio of slip deficit rate to relative plate motion rate. Contour lines show the resulting coseismic slip magnitudes in meters for the cases where rake of slip is opposite slip deficit (see Table 1 for peak slip values). (d) Calculated vertical surface displacement for the four kinematic coupling-based models. Locations 1-4 referenced in text.

The Nankai Trough, located just offshore of southwestern Japan (Figure 1a), is ideal for testing the utility of recent, geodetically constrained estimates of interseismic coupling in constructing future rupture scenarios. Following the unexpectedly severe 2011 Tohoku earthquake, Japan's government called for hazard assessment research to focus on defining worst-case scenarios for earthquakes and tsunamis impacting the country (Central Disaster Management Council, 2012). This guideline has focused attention on the Nankai Trough, where the subduction of the Philippine Sea Plate beneath the southwest Japan forearc is predicted to generate a magnitude 8-9 earthquake within the next few decades (Headquarters for Earthquake Research Promotion, 2013). Thirteen hundred years of historical records document Nankai earthquakes occurring every 100-200 years (Ishibashi, 1999), and numerous studies have documented $\sim 8,000$ years of land-based geologic evidence for Nankai earthquakes (Garrett et al., 2016, and references therein). The largest known historical Nankai earthquake occurred in CE 1707 and is thought to have simultaneously ruptured the majority of the trough, extending from Suruga Bay southwest to Hyūga-nada (i.e., the full length shown in Figure 1a). Documentation of the resultant tsunami height reaches $10 \mathrm{~m}$ in the most severely impacted areas along the open Pacific coastline of Shikoku, Japan (Hatori, 1974, 1985; Murakami et al., 1995).

Japan's extensive GEONET Global Positioning System (GPS) network has measured crustal motion across the Japanese Islands since 1996, and several studies have utilized this dataset to estimate the distribution of 
interseismic coupling for the Nankai Trough (Loveless \& Meade, 2016; T. Nishimura et al., 2018; S. Nishimura \& Hashimoto, 2006; Yokota et al., 2016). These coupling estimates differ in detail depending on whether or not the contributions of crustal block motion to the GPS velocity field are considered, and whether or not seafloor geodetic measurements are used in addition to land-based GEONET data. However, the resultant spatial distributions of coupling in these studies are broadly similar. In particular, strong coupling is estimated along the Nankai interface from Kyushu to the Tokai region, with concentrations offshore Shikoku and the Kii Peninsula, coincident with the estimated rupture areas of the great 1944 and 1946 earthquakes (e.g., Sagiya \& Thatcher, 1999).

There are also several published rupture scenarios for a future worst-case Nankai earthquake that draw on geophysical, geologic, and historical investigations of the trough. A series of simple, kinematic source models (models of coseismic slip that do not consider stress conditions or the fault's physical properties) have been formulated to match historical and geologic records of ground shaking and tsunamigenic flooding from the 1707 earthquake, which is often considered a worst-case event (Aida, 1981; Ando, 1975; An'naka et al., 2003; Furumura et al., 2011). As geophysical studies have enabled physical characterization of the Nankai subduction interface, large rupture scenarios have also been generated from dynamic and quasi-dynamic simulations that solve the spatiotemporal evolution of slip by incorporating the trough's geometry, geologic structure, and frictional properties (Hok et al., 2011; Hyodo \& Hori, 2013; Kodaira et al., 2006). Dynamic simulations consider inertial effects, while quasi-dynamic simulations approximate them with a radiation damping term. One kinematic model of the 1707 earthquake used an interseismic coupling distribution to support extending its rupture area (Furumura et al., 2011), and one dynamic simulation used slip deficit rates to define an initial stress distribution (Hok et al., 2011); however, there is no rupture scenario based solely on the spatial correlation between coupling and slip. Furthermore, we emphasize that our interseismic coupling estimates consider crustal block motion in southwestern Japan, which reduces potential biases in moment accumulation on the Nankai subduction interface that may arise by neglecting this motion.

\section{Methods}

Here we create a set of four new kinematic rupture models for the Nankai Trough by linearly scaling estimated interseismic coupling to coseismic slip. We use temporally averaged coupling fraction distributions estimated with elastic block models (Loveless \& Meade, 2016; supporting information Text S1). This technique simultaneously considers the contributions to the geodetic velocity field from interplate coupling and crustal block motion. Near-trench coupling is poorly resolved, in part due to the scarcity of seafloor geodetic data (T. Nishimura et al., 2018; Yasuda et al., 2017; Yokota et al., 2016); thus, following Loveless and Meade (2016), we adopt two candidate coupling scenarios (Figure 1c): one in which nonzero slip deficit can be estimated along the trench ("trench-coupled" scenario) and one in which the subduction interface around the trench is assumed not to accumulate slip deficit ("trench-creeping" scenario). When translating coupling to coseismic slip for the trench-coupled and trench-creeping cases, we also test two methods for determining the rake (direction) of slip: (1) opposite the direction of accumulated slip deficit and (2) opposite the direction of relative plate motion (supporting information Text S1). Of the four slip models, we favor the trenchcoupled distribution with rake of slip opposite the direction of slip deficit. Direct observations from drilling (Sakaguchi et al., 2011) and new coupling estimates that incorporate a few years of seafloor geodetic measurements (Yokota et al., 2016) both indicate that coupling at the trench is likely, and the first rake method produces a fanning pattern of coseismic rakes around concentrations of slip that is consistent with spatially variable slip magnitudes. Although we favor this one scenario, considering all four better represents the uncertainty in our methodology for scaling a given coupling distribution to slip, and it addresses the possibility that coupling near the trench might not necessarily translate to shallow coseismic slip (e.g., Ide et al., 2011).

Finally, we test a range of peak slip magnitudes for the linear scaling of coupling to slip. The Nankai Trough is currently coupled along its entire length (Figure 1b), so we scale slip to generate an event comparable to the most recent full-margin Nankai rupture in 1707. There are no measurements of the 1707 earthquake's magnitude, but historical records document the resultant tsunami's height (Hatori, 1974, 1985; Murakami et al., 1995); thus, we simulate tsunami inundation with a range of peak slip magnitudes for each of the four coupling-based slip distributions and choose the value that produces the best match between modeled 
Table 1

Best Fit Peak Slip Values and Associated Seismic Moments, Moment Magnitudes, and Return Periods (Based on Estimated Slip Deficit Rates) for the Four Coupling-Based Rupture Scenarios

\begin{tabular}{|c|c|c|c|c|c|}
\hline Near-trench behavior & Slip rake & Peak slip (m) & $m_{0}\left(\mathrm{~N}-\mathrm{m} \times 10^{22}\right)$ & $M_{w}$ & Return period (years) \\
\hline Coupled & Opposite slip deficit & 16 & 3.43 & 8.99 & 236 \\
\hline Coupled & Opposite relative plate motion & 26 & 4.22 & 9.05 & 384 \\
\hline Creeping & Opposite slip deficit & 18 & 2.69 & 8.92 & 286 \\
\hline Creeping & Opposite relative plate motion & 20 & 2.60 & 8.91 & 257 \\
\hline
\end{tabular}

and observed 1707 tsunami heights. We perform tsunami inundation simulations using version 5.3 .0 of the open source tsunami model GeoClaw (Berger et al., 2011; Clawpack Development Team, 2015; Mandli et al., 2016), which is a subset of Clawpack. Earthquake sources for tsunami simulations, GeoClaw model parameters, development of a topographic model, and methodology for comparing modeled and historical tsunami inundation heights are all described in detail in supporting information Texts S2-S4 and Figure S1.

\section{Results and Discussion}

Table 1 provides the best fit peak slip values and associated seismic moments $\left(m_{0}\right)$, moment magnitudes, and return periods for each coupling-based rupture scenario. Return periods are calculated using the scenario slip magnitudes and estimated slip deficit rates from the block models. Estimated seismic moments are consistent among the four scenarios, with the average internal $m_{0}$ deviation equaling $16 \%$ of the average estimated $m_{0}$. Scenario return periods range from 236 to 384 years. In paleoseismic studies, Nankai earthquake recurrence intervals are poorly constrained due to uncertainty in event chronology, event magnitude, and flood threshold characterization (Garrett et al., 2016). However, historical records indicate that full-length Nankai ruptures occurred in CE 1707, 1361, and 684 (Garrett et al., 2016, and references therein). Our calculated 236- to 384-year return period for the accumulated Nankai Trough slip deficit is similar to the return periods for the two most recent historical full-margin events in CE 1707 and 1361, and slightly shorter when considering three events between the present and CE 684.

Figures $1 \mathrm{c}$ and $1 \mathrm{~d}$ show modeled coupling distributions, slip magnitudes, and vertical ground surface displacements for the four rupture scenarios. The trench-creeping and trench-coupled scenarios differ principally in terms of the downdip locations of concentrated slip. Because of the enforced creep at the shallowest portion of the interface in the trench-creeping models, the downdip gradient in coupling, and hence scenario slip, is steeper than in the trench-coupled models. This variation in downdip locus of slip yields vertical displacement patterns showing a similar shift: peak uplift and subsidence calculated from the trench-creeping models are located farther northwest than those of the trench-coupled models, which feature peak slip near the trench. The along-strike slip concentrations near Shikoku and the Kii Peninsula are consistent between the trench-coupled and trench-creeping cases and are broadly consistent with other estimates of interseismic coupling (e.g., Yokota et al., 2016). Distributions of modeled ground surface displacement differ for the two methods of assigning rake of slip: the along-strike variation in uplift is smoother for scenarios with rake opposite the direction of relative plate motion and more spatially variable with smaller regions of focused uplift for scenarios with rake opposite the direction of slip deficit.

Modeled vertical ground surface displacement also has varying agreement with geologic evidence for past coseismic uplift and subsidence. There is robust geologic evidence for uplift associated with Nankai earthquakes at Cape Muroto (Iryu et al., 2009; Maemoku, 1988, 2001) and the southern tip of the Kii Peninsula (Shishikura et al., 2008; Shishikura, 2013; locations 1 and 2, respectively, in Figure 1d). There is also a potential indication of uplift in southwestern Shizuoka prefecture (Azuma et al., 2005; Fujiwara, Ono, et al., 2007, Fujiwara et al., 2010) and subsidence at in Suruga Bay (Fujiwara, Sawai, et al., 2007; Fujiwara et al., 2016; locations 3 and 4 in Figure 1d), but the connection between deformation to Nankai earthquakes is more uncertain at these sites (Garrett et al., 2016). Three of the four coupling-based models reproduce the observed uplift around Cape Muroto and the Kii Peninsula, but they do not consistently reproduce the uplift in Shizuoka and subsidence in Suruga Bay. The Kochi Plain also subsided $\sim 60 \mathrm{~cm}$ during the 1946 Nankai earthquake (Geographical Survey Institute of Japan, 1952; Miyabe, 1955). Although subsidence 
a

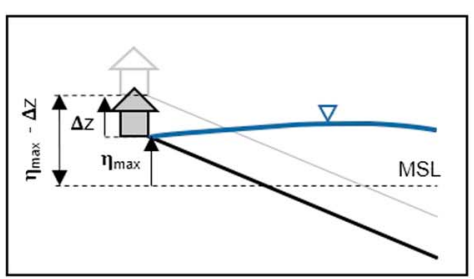

C

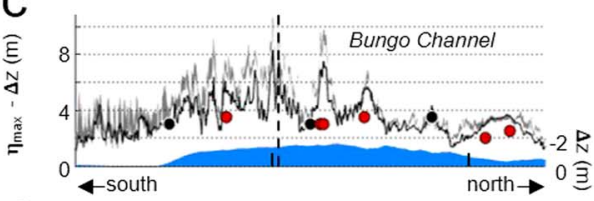

b

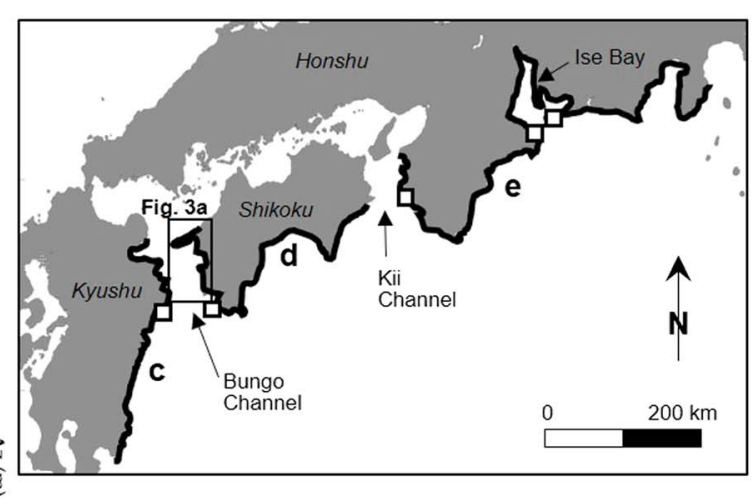

d

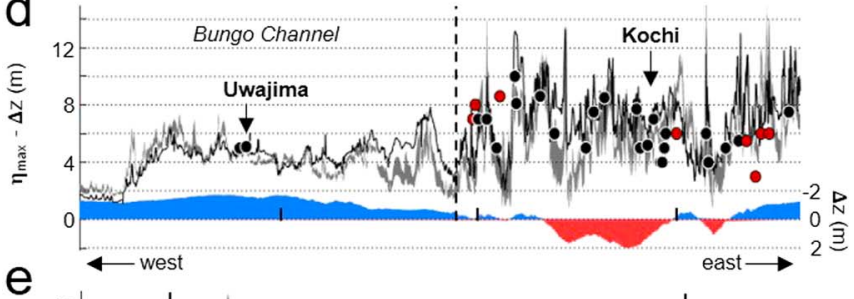

e

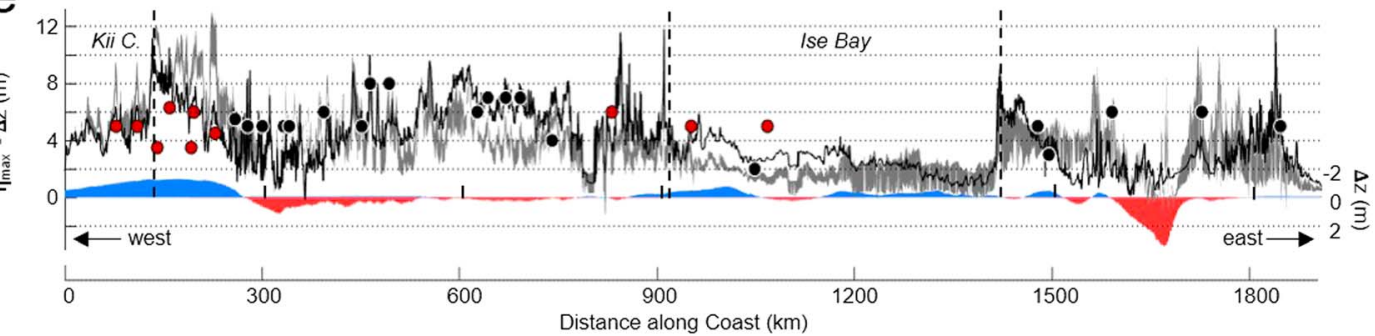

Figure 2. Modeled inundation heights due to both tsunami and vertical land movement. (a) Illustration of maximum total water level change, $\eta_{\max }-\Delta z$ (left-hand $y$ axis in [c]-[e]), where $\Delta z=$ vertical ground surface displacement (right-hand $y$ axis in [c]-[e]), and $\eta_{\max }=$ maximum tsunami height above mean sea level (MSL). (b) Regional coastline near the Nankai Trough, where distance is mapped on $x$ axes in (c)-(e). White squares mark transitions between open Pacific and relatively sheltered coastlines. (c-e) $\eta_{\max }-\Delta z$ along coastlines for the $\mathrm{H} 14$ scenario (black line) and the four couplingbased scenarios in Table 1 (gray line with shading shows range for four cases). Blue and red filled regions centered at zero show the contributions of subsidence (negative $\Delta z$ ) and uplift (positive $\Delta z$ ), respectively, to total relative water level change (i.e., $\eta_{\max }-\Delta z$ ). Circles represent observed 1707 tsunami inundation heights (Hatori, 1974, 1985; Murakami et al., 1995; black if the discrepancy between modeled and observed tsunami heights is $<25 \%$ of the observed height, and red if not). Vertical dashed lines in (c)-(e) denote locations of squares in (b).

around Kochi is commonly cited as a feature of Nankai earthquakes (e.g., Ando, 1975; Furumura et al., 2011), our coupling-based simulations do not produce this subsidence. Hyodo et al. (2014) conducted a series of modeling experiments demonstrating that slip on the downdip extent of the Nankai subduction interface reduces Pacific coastal subsidence and lowers tsunami heights such that they are more consistent with historical observations of the 1707 event. This is consistent with our coupling-based rupture scenarios, where the strongly coupled patch of the subduction interface underlying Shikoku produces large slip on its downdip extent (Figure 1d), and modeled tsunami heights largely agree with 1707 observations on Shikoku's Pacific coast (Figure 2d).

The spatial distributions of modeled tsunami inundation are internally consistent among the four couplingbased scenarios (gray line with shading in Figures 2c-2e shows the range). Along most of the coast, tsunami heights vary by less than $0.5 \mathrm{~m}$ among scenarios, and larger inconsistencies are generally due to local variation in vertical ground surface deformation. The purpose of these tsunami simulations is to validate couplingbased rupture models against observations of the 1707 Nankai event of record; thus, we do not attempt to provide detailed sensitivity testing and modeled inundation analysis that would be required for tsunami simulations intended for hazard mitigation. 
Along most of the Nankai Trough, the spatial distribution of flooding from the scaled, coupling-based model tsunamis compares favorably with the distribution of observed 1707 tsunami heights (circles in Figures $2 \mathrm{c}-2 \mathrm{e}$ ). This general consistency indicates that contemporary coupling along the trough mirrors the slip distribution of a full-margin, 1707-type rupture. The model-observation fit is particularly consistent in Shikoku and Honshu, where the most historical observations are available. For 25 of 33 observations in Shikoku and 20 of 30 observations in Honshu, the discrepancy between the coupling-based model and the observed tsunami height is less than $25 \%$ of the observed height (supporting information Text S5). In Kyushu, three of the nine available observations of the 1707 tsunami are matched. General model exceedance for the remaining six could be due to uncertainty in the limited number of historical observations available for this region (Ando, 1975; Ishibashi, 2004; Murakami et al., 1995). These six unmatched Kyushu observations are also clustered around a strongly coupled patch of the Nankai interface south of the Bungo Channel (Figures 1c and 2c). In this region there are known slow-slip events (Ozawa et al., 2013), and the coupling fraction has varied since 1996 (Loveless \& Meade, 2016), potentially adding uncertainty to the local modeled slip distribution.

Figure 2 also highlights the contribution of coseismic uplift and subsidence to tsunamigenic flooding along Japan's coast. Vertical ground displacement changes maximum flood heights by 1-2 $\mathrm{m}$ along more than half of the coastline shown in Figure 2, and subsidence accounts for a significant fraction of the total inundation height along major coastline segments on all three mainland islands. In western Shikoku in particular, focused coseismic subsidence contributes to unexpectedly large flood heights (up to $7 \mathrm{~m}$ ) in the Bungo Channel region that otherwise would be relatively sheltered from Nankai Trough tsunamis (Figures 1d and 2d).

We focus attention on validating the identified region of subsidence in the Bungo Channel (Figure 1a) both because the area contains Shikoku's sole nuclear power plant (Ikata Power Plant) and because historical records for the 1707 tsunami along the west coast of Shikoku are geographically limited to the Uwajima embayment, where 4-5 m of inundation was recorded (Figure $2 \mathrm{~d}$ ). Over the duration of each tsunami simulation, we monitor water level with model tide gauges at two locations within this subsided region (Figure 3): one within the Uwajima embayment and two at Lake Ryuuoo. Lake Ryuuoo is the site of a recent back-barrier sedimentological reconstruction that provided $4 \mathrm{~m}$ as the region's first physically based 1707 tsunami inundation height constraint (Baranes et al., 2016). At Uwajima, $\sim 2 \mathrm{~m}$ of coseismic subsidence and a $\sim 2.5 \mathrm{~m}$ tsunami combine to match historical documentation of a 4-5 m tsunami impacting the city in 1707 (Figure 3c; Murakami et al., 1995). At Lake Ryuuoo, subsidence lowers the barrier beach separating the lake from the ocean by nearly $2 \mathrm{~m}$. This subsidence allows for barrier inundation by the 1707 tsunami and is required to explain a marine flood deposit within Lake Ryuuoo's sediment that dates to the event (Figure 3d; Baranes et al., 2016). Coupling-based rupture scenarios, the Lake Ryuuoo sedimentary record, and historical observations therefore provide three independent lines of evidence for substantial subsidence on the eastern side of the Bungo Channel.

As a final means of validation, we compare our kinematic coupling-based models to the independent, quasidynamic "larger-earthquake scenario" from Hyodo et al. $\left(2014 ; M_{w}=9.03 ; m_{0}=4.37 \times 10^{22} \mathrm{~N}\right.$-m; peak slip $=20.6 \mathrm{~m}$ ), hereafter referred to as $\mathrm{H} 14$. The H14 slip distribution is based on the geometry, geologic structure, and frictional properties of the Nankai Trough inferred from geophysical studies. Like our two trenchcoupled rupture scenarios, the $\mathrm{H} 14$ model also allows for slip at the trench axis. Estimated seismic moments are consistent among the $\mathrm{H} 14$ and the two trench-coupled scenarios, with the average internal $\mathrm{M}_{0}$ deviation equaling $16 \%$ of the average estimated $M_{0}$. Figures $1 \mathrm{~b}$ and $1 \mathrm{~d}$ also illustrate the similar pattern of vertical ground surface displacement produced by the independent kinematic and quasi-dynamic modeling techniques. The spatial extent of rupture is nearly identical for the two cases, and both include slip on the downdip extent of the subduction interface that yields a focused region of subsidence around western Shikoku (eastern side of the Bungo Channel). For the coupling-based models, the transition from offshore uplift to inland subsidence generally occurs farther to the northwest, and the pattern of ground surface deformation is more complex. The greater complexity is to be expected, given that the coupling-based models are based on GPS data, while the H14 model is based on a smoother set of defined fault characteristics (Figure 3 in Hyodo \& Hori, 2013).

The kinematic and quasi-dynamic scenarios also produce a consistent distribution of modeled tsunami inundation along the Kyushu, Shikoku, and Honshu coastlines (Figure 2; methods described in supporting 
a

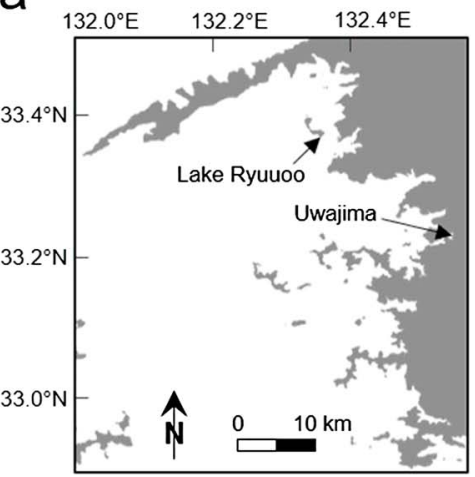

C

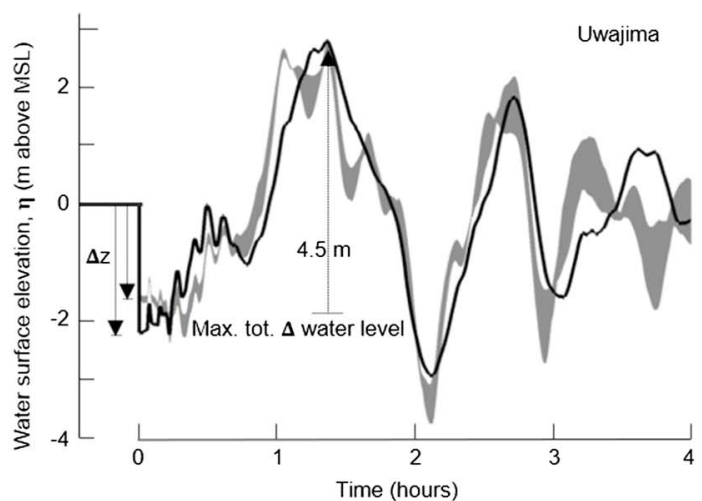

b

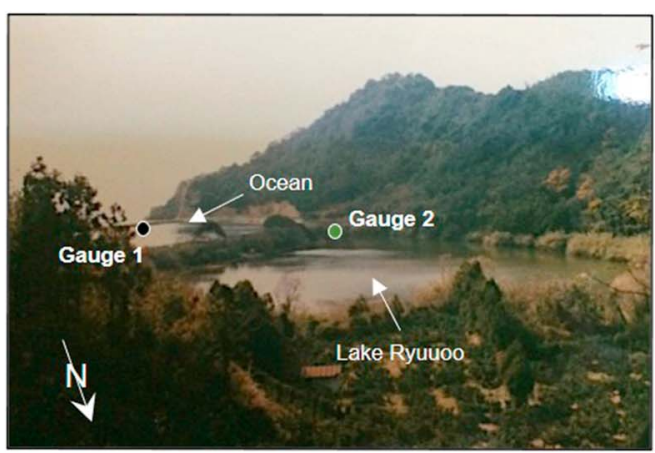

d

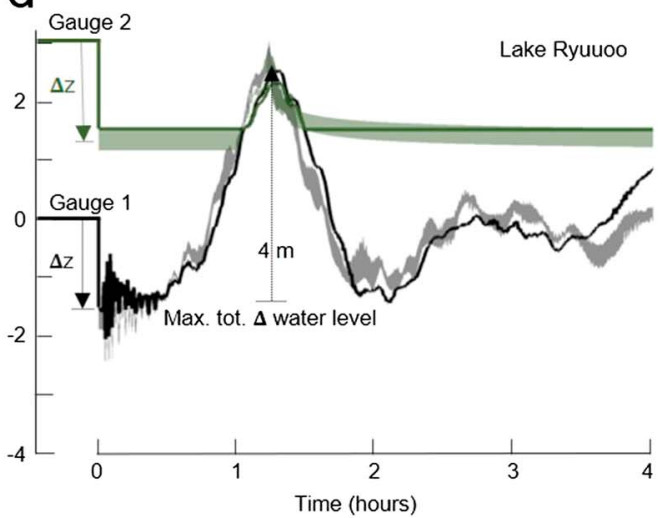

Figure 3. Model gauge results in the Bungo Channel region of focused subsidence. (a) Northwestern Shikoku model gauge locations (see Figure 1 for regional context). (b) Photograph of Lake Ryuuoo showing locations of model gauges, where Gauge 1 is offshore, and Gauge 2 is on the lowest-elevation area of Lake Ryuuoo's barrier beach. (c) Uwajima and (d) Lake Ryuuoo gauge results for the $\mathrm{H} 14$ scenario (green and black solid lines for Gauges 1 and 2, respectively), and the four coupling-based scenarios (green and black shaded regions). Note in (d) how subsidence ( $\Delta z$ ) is required for the observed inundation of Lake Ryuuoo's barrier beach (Gauge 2). MSL = mean sea level.

information Texts S2-S4). Maximum tsunami heights are generally within $2 \mathrm{~m}$ of each other, and spatial variation in modeled inundation is similar over both 100- and 1000-km scale distances along impacted coastlines of Japan. Furthermore, similar to the coupling-based scenario results, subsidence in the H14 model enables the tsunami to inundate Lake Ryuuoo (Figure 3d). The quasi-dynamic modeling approach in $\mathrm{H} 14$ is therefore consistent not only with kinematic coupling-based scenarios but also with sedimentological evidence for subsidence in the region. These similarities in simulated seismic moment, ground surface displacement, and tsunami inundation between the coupling-based and $\mathrm{H} 14$ models both support the scaling of coupling to slip as a valid tool for generating rupture scenarios and demonstrate the connection between modern geodetic measurements of surface motion and physical characteristics of the subduction interface.

\section{Conclusions}

This study demonstrates methods for constructing and evaluating rupture scenarios based on the scaling of interseismic coupling to coseismic slip. Results show similarities in ground surface deformation and tsunami inundation among kinematic coupling-based Nankai Trough rupture scenarios, historical, and geologic records of the 1707 earthquake and tsunami, and the independent, quasi-dynamic H14 model. Study implications include the following:

1. Contemporary coupling mirrors the slip distribution of a full-margin, 1707-type rupture of the Nankai Trough. 
Acknowledgments

Funding was provided by the U.S. National Science Foundation (award 1630090) and the National Aeronautics and Space Administration (award NNX16AO24H S02). We thank K. Imai for providing us with historical tsunami heights compiled from existing studies. Ground surface displacements for the coupling-based scenarios are provided in the supporting information. Sources for coupling distributions, topographic data used in tsunami simulations, 1707 tsunami historical observations, and the GeoClaw code are provided in the references.
2. Coupling-based rupture scenarios, historical observations from Uwajima, the Lake Ryuuoo sedimentological record, and the $\mathrm{H} 14$ quasi-dynamic model all independently support focused coseismic subsidence in western Shikoku.

3. There is a connection between geodetic measurements of surface motion and physical properties of the subduction interface.

\section{References}

Aida, I. (1981). Numerical experiments for the tsunamis generated off the coast of the Nankaido district. Bulletin of the Earthquake Research Institute, 56, 713-730.

Amante, C., \& Eakins, B. W. (2011). ETOPO1 1 arc-minute global relief model. National Geographic Data Center, NOAA. https://doi.org/10.7289/ V5C8276M

Ando, M. (1975). Source mechanisms and tectonic significance of historical earthquakes along the Nankai Trough, Japan. Tectonophysics, 27(2), 119-140. https://doi.org/10.1016/0040-1951(75)90102-X

An'naka, T., Inagaki, K., Tanaka, H., \& Yanagisawa, K. (2003). Characteristics of great earthquakes along the Nankai trough based on numerical tsunami simulation. Journal of Earthquake Engineering, 27, 307.

Arcos, M. E. M., \& LeVeque, R. J. (2015). Validating velocities in the GeoClaw tsunami model using observations near Hawaii from the 2011 Tohoku tsunami. Pure and Applied Geophysics, 172(3-4), 849-867. https://doi.org/10.1007/s00024-014-0980-y

Azuma, T., Ota, Y., Ishikawa, M., \& Taniguchi, K. (2005). Late Quaternary coastal tectonics and development of marine terraces in Omaezaki, Pacific coast of central Japan. Daiyonki-Kenkyu, 44(3), 169-176. https://doi.org/10.4116/jaqua.44.169

Baranes, H. E., Woodruff, J. D., Wallace, D. J., Kanamaru, K., \& Cook, T. L. (2016). Sedimentological records of the C.E. 1707 Hoei Nankai Trough tsunami in the Bungo Channel, southwestern Japan. Natural Hazards, 84(2), 1185-1205. https://doi.org/10.1007/s11069-016-2498-3

Berger, M. J., George, D. L., Leveque, R. J., \& Mandli, K. T. (2011). The GeoClaw software for depth-averaged flows with adaptive refinement. Advances in Water Resources, 34(9), 1195-1206. https://doi.org/10.1016/j.advwatres.2011.02.016

Central Disaster Management Council (2012). Final report-Toward the reconstruction for sound and unwavering Japan. Retrieved from http://www.bousai.go.jp/kaigirep/chuobou/suishinkaigi/english/pdf/FinalReport.pdf\#page=1

Clawpack Development Team (2015). Clawpack version 5.3.0. Retrieved from http://www.clawpack.org

Feigl, K. L., Agnew, D. C., Bock, Y., Dong, D., Donnellan, A., Hager, B. H., et al. (1993). Space geodetic measurement of crustal deformation in central and southern California. Journal of Geophysical Research, 98, 21,677-21,712. https://doi.org/10.1029/93JB02405

Fujiwara, O., Fujino, S., Komatsubara, J., Morita, Y., \& Namegaya, Y. (2016). Paleoecological evidence for coastal subsidence during five great earthquakes in the past 1500 years along the northern onshore continuation of the Nankai subduction zone. Quaternary International, 397, 523-540. https://doi.org/10.1016/j.quaint.2015.11.014

Fujiwara, O., Hirakawa, K., Irizuki, T., Hasegawa, S., Hase, Y., Uchida, J., \& Abe, K. (2010). Millennium-scale recurrent uplift from beach deposits bordering the eastern Nankai Trough, Omaezaki area, central Japan. Island Arc, 19(3), 374-388. https://doi.org/10.1111/ j.1440-1738.2010.00729.x

Fujiwara, O., Ono, E., Satake, K., Sawai, Y., Umitsu, M., Yata, T., et al. (2007). Trace of the AD1707 Hoei earthquake from the coastal lowland, Shizuoka Prefecture, central Japan. Annual Report on Active Fault and Paleoearthquake Researches, 7, 157-171.

Fujiwara, O., Sawai, Y., Morita, Y., Komatsubara, J., \& Abe, K. (2007). Coseismic subsidence recorded in the Holocene sequence in the Ukishima-ga-hara lowland, Shizuoka Prefecture, central Japan. Annual Report on Active Fault and Paleoearthquake Researches, 7, 91-118.

Furumura, T., Imai, K., \& Maeda, T. (2011). A revised tsunami source model for the 1707 Hoei earthquake and simulation of tsunami inundation of Ryujin Lake, Kyushu, Japan. Journal of Geophysical Research, 116, B02308. https://doi.org/10.1029/2010JB007918

Furuse, N., \& Kono, Y. (2003). Slab residual gravity anomaly: Gravity reduction due to subducting plates beneath the Japanese Islands. Journal of Geodynamics, 36(4), 497-514. https://doi.org/10.1016/S0264-3707(03)00062-0

Garrett, E., Fujiwara, O., Garrett, P., Heyvaert, V. M. A., Shishikura, M., \& Yokoyama, Y. (2016). A systematic review of geological evidence for Holocene earthquakes and tsunamis along the Nankai-Suruga Trough, Japan. Earth-Science Reviews, 159, 337-357. https://doi.org/ 10.1016/j.earscirev.2016.06.011

Geodetic Observation Center (2015). Geospatial Information Authority of Japan. GEONET. Retrieved from http://terras.gsi.go.jp

Geographical Survey Institute of Japan (1952). Resurvey of the southwestern part of Japan after the great Nankaido earthquake of 1946. Bulletin of the Geographical Survey Institute, 3(Part 1), 31-118.

González, F., LeVeque, R. J., Varkovitsky, J., Chamberlain, P., Hirai, B., \& George, D. L. (2011). GeoClaw Results for the NTHMP tsunami benchmark problems. Retrieved from http://www.clawpack.org/links/nthmp-benchmarks/geoclaw-results

Hager, B. H., King, R. W., \& Murray, M. H. (1991). Measurement of crustal deformation using the global positioning system. Annual Review of Earth and Planetary Sciences, 19, 351-382. https://doi.org/10.1146/annurev.ea.19.050191.002031

Hatori, T. (1974). Sources of large tsunamis in southwest Japan. Journal of the Seismological Society of Japan, 27, 10-24.

Hatori, T. (1985). Field investigation of historical tsunamis along the east coast of Kyushu, West Japan. Bulletin. Earthquake Research Institute, University of Tokyo, 60, 439-459.

Headquarters for Earthquake Research Promotion (2013). Long-term evaluation of Nankai trough earthquakes (revised version). Retrieved from http://www.jishin.go.jp/main/chousa/kaikou_pdf/nankai_2.pdf

Hok, S., Fukuyama, E., \& Hashimoto, C. (2011). Dynamic rupture scenarios of anticipated Nankai-Tonankai earthquakes, southwest Japan. Journal of Geophysical Research, 116, B12319. https://doi.org/10.1029/2011JB008492

Hyodo, M., \& Hori, T. (2013). Re-examination of possible great interplate earthquake scenarios in the Nankai Trough, southwest Japan, based on recent findings and numerical simulations. Tectonophysics, 600, 175-186. https://doi.org/10.1016/j.tecto.2013.02.038

Hyodo, M., Hori, T., Ando, K., \& Baba, T. (2014). The possibility of deeper or shallower extent of the source area of Nankai Trough earthquakes based on the 1707 Hoei tsunami heights along the Pacific and Seto Inland Sea coasts, southwest Japan. Earth, Planets and Space, 66(1), 123. https://doi.org/10.1186/1880-5981-66-123

Ide, S., Baltay, A., \& Beroza, G. C. (2011). Shallow dynamic overshoot and energetic deep rupture in the 2011 Mw 9.0 Tohoku-Oki earthquake. Science, 332(6036), 1426-1429. https://doi.org/10.1126/science.1207020

Iryu, Y., Maemoku, H., Yamada, T., \& Maeda, Y. (2009). Limestones as a paleobathymeter for reconstructing past seismic activities: Muroto-misaki, Shikoku, southwestern Japan. Global and Planetary Change, 66, 52-64. https://doi.org/10.1016/j.gloplacha.2008.03.009 
Ishibashi, K. (1999). Great Tokai and Nankai, Japan, earthquakes as revealed by historical seismology: 1. Review of the events until the mid-14th century. Chigaku Zasshi, 108(4), 399-423. https://doi.org/10.5026/jgeography.108.4_399

Ishibashi, K. (2004). Status of historical seismology in Japan. Annals of Geophysics, 47(2-3), 339-368.

Kaneko, Y., Avouac, J., \& Lapusta, N. (2010). Towards inferring earthquake patterns from geodetic observations of interseismic coupling. Nature Geoscience, 3, 363-369. https://doi.org/10.1038/ngeo843

Kodaira, S., Hori, T., Ito, A., Miura, S., Fujie, G., Park, J., et al. (2006). A cause of rupture segmentation and synchronization in the Nankai Trough revealed by seismic imaging and numerical simulation. Journal of Geophysical Research, 111, B09301. https://doi.org/10.1029/ 2005JB004030

LeVeque, R. J., \& George, D. L. (2008). High-resolution finite volume methods for the shallow water equations with bathymetry and dry states. In P. L. F. Liu, H. Yeh, \& C. Synolakis (Eds.), Advanced numerical models for simulating tsunami waves and runup (pp. 43-73). Singapore: World Scientific.

LeVeque, R. J., George, D. L., \& Berger, M. J. (2011). Tsunami modeling with adaptively refined finite volume methods. Acta Numer, 20, 211-289. https://doi.org/10.1017/S0962492911000043

Loveless, J. P., \& Meade, B. J. (2011). Spatial correlation of interseismic coupling and coseismic rupture extent of the $2011 \mathrm{M}_{\mathrm{W}}=9.0$ Tohoku-oki earthquake. Geophysical Research Letters, 38, L17306. https://doi.org/10.1029/2011GL048561

Loveless, J. P., \& Meade, B. J. (2016). Two decades of spatiotemporal variations in subduction zone coupling offshore Japan. Earth and Planetary Science Letters, 436, 19-30. https://doi.org/10.1016/j.epsl.2015.12.033

Maemoku, H. (1988). Holocene crustal movement in Muroto Peninsula, southwest Japan. Geographical Review of Japan, Series A, 61, 747-769.

Maemoku, H. (2001). Reexamination of coseismic uplift of Cape Muroto, southwestern Japan, using AMS 14C ages of raised sessile organisms. Chigaku Zasshi, 110, 479-490. https://doi.org/10.5026/jgeography.110.4_479

Mandli, K. T., Ahmadia, A. J., Berger, M., Calhoun, D., George, D. L., Hadjimichael, Y., et al. (2016). Clawpack: Building an open source ecosystem for solving hyperbolic PDEs. PeerJ Computer Science, 2, e68. https://doi.org/10.7717/peerj-cs.68

McCaffrey, R., Long, M. D., Goldfinger, C., Zwick, P. C., Nabelek, J. L., Johnson, C. K., \& Smith, C. (2000). Rotation and plate locking at the southern Cascadia subduction zone. Geophysical Research Letters, 27, 3117-3139. https://doi.org/10.1029/2000GL011768

Meade, B. J. (2007). Algorithms for the calculation of exact displacements, strains, and stresses for triangular dislocation elements in a uniform elastic half space. Computers \& Geosciences, 33(8), 1064-1075. https://doi.org/10.1016/j.cageo.2006.12.003

Miyabe, N. (1955). Vertical earth movements in the Nankai district. Bulletin of the Geographical Survey Institute, 4, 1-14.

Moreno, M., Rosenau, M., \& Oncken, O. (2010). 2010 Maule earthquake slip correlates with pre-seismic locking of Andean subduction zone. Nature, 467, 198-202. https://doi.org/10.1038/nature09349

Murakami, H., Itoh, S., Hiraiwa, Y., \& Shimada, T. (1995). Re-examination of historical tsunamis in Shikoku Island, Japan. In Y. Tsuchiya \& N. Shuto (Eds.), Tsunami: Progress in prediction, disaster prevention and warning (pp. 197-210). Dordrecht, Netherlands: Kluwer Academic Publishers.

Nishimura, S., \& Hashimoto, M. (2006). A model with rigid rotations and slip deficits for the GPS-derived velocity field in Southwest Japan Tectonophysics, 421(3-4), 187-207. https://doi.org/10.1016/j.tecto.2006.04.017

Nishimura, T., Yokota, Y., Tadokoro, K., \& Ochi, T. (2018). Strain partitioning and interplate coupling along the northern margin of the Philippine Sea plate, estimated from Global Navigation Satellite System and Global Positioning System-Acoustic data. Geosphere, 14(2). https://doi.org/10.1130/GES01529.1

Ozawa, S., Yarai, H., Imakiire, T., \& Tobita, M. (2013). Spatial and temporal evolution of the long-term slow slip in the Bungo Channel, Japan. Earth, Planets and Space, 65(2), 67-73. https://doi.org/10.5047/eps.2012.06.009

Protti, M., González, V., Newman, A. V., Dixon, T. H., Schwartz, S. Y., Marshall, J. S., et al. (2014). Nicoya earthquake rupture anticipated by geodetic measurement of the locked plate interface. Nature Geoscience, 7, 117-121. https://doi.org/10.1038/ngeo2038

Sagiya, T., Miyazaki, S., \& Tada, T. (2000). Continuous GPS array and present-day crustal deformation of Japan. Pure and Applied Geophysics, 157(11-12), 2303-2322. https://doi.org/10.1007/PL00022507

Sagiya, T., \& Thatcher, W. (1999). Coseismic slip resolution along a plate boundary megathrust: The Nankai Trough, southwest Japan. Journal of Geophysical Research, 104, 1111-1129. https://doi.org/10.1029/98JB02644

Sakaguchi, A., Chester, F., Curewitz, D., Fabbri, O., Goldsby, D., Kimura, G., et al. (2011). Seismic slip propagation to the up-dip end of plate boundary subduction interface faults: Vitrinite reflectance geothermometry on Integrated Ocean Drilling Program NanTroSEIZE cores. Geology, 39(4), 395-398. https://doi.org/10.1130/G31642.1

Shishikura, M. (2013). Earthquake and tsunamis along the Nankai Trough, inferred from geology and geomorphology-Examples in Nanka region. Geological Survey Institute of Japan Chishitsu News, 2, 201-204.

Shishikura, M., Echigo, T., Maemoku, H., \& Ishiyama, T. (2008). Height and ages of uplifted sessile assemblage distributed along the southern coast of the Kii Peninsula, south-central Japan-Reconstruction of multi-segment earthquake history along the Nankai Trough. Annual Report on Active Fault and Paleoearthquake Researches, 8, 267-280.

Yasuda, K., Tadokoro, K., Taniguchi, S., Kimura, H., \& Matsuhiro, K. (2017). Interplate locking condition derived from seafloor geodetic observation in the shallowest subduction segment at the Central Nankai Trough, Japan. Geophysical Research Letters, 44, 3572-3579. https://doi.org/10.1002/2017GL072918

Yokota, Y., Ishikawa, T., Watanabe, S., Tashiro, T., \& Asada, A. (2016). Seafloor geodetic constraints on interplate coupling of the Nankai Trough megathrust zone. Nature, 534, 374-377. https://doi.org/10.1038/nature17632 